\title{
Repensando el Estado y la política desde la autonomía indígena: la construcción del Gobierno Territorial Autónomo de la Nación Wampis***
}

\author{
Tania Gómez ${ }^{* * *}$
}

\begin{abstract}
Este artículo se basa en mi tesis de licenciatura «Reinventar el Estado desde la autonomía indígena: un rastreo del proceso de la articulación del Gobierno Territorial Autónomo de la Nación Wampis (GTANW)» (2019).

El siguiente artículo no podría haber sido realizado sin el apoyo y la confianza de líderes y liderezas wampis del Amazonas y Loreto, a quienes agradezco profundamente. Se debe seguir avanzando en el entendimiento de las estrategias de autonomía indígena en el Perú. No solo desde la labor histórica académica, sino como una discusión de las memorias y lecturas políticas de los proyectos que los pueblos indígenas construyen. Esa es la tarea pendiente a la que esperamos aportar.

"'Licenciada en Sociología por la Pontificia Universidad Católica del Perú. Actualmente es asistente de investigación del Instituto de Estudios Peruanos (IEP).Correo electrónico: tania.gomez@pucp.pe
\end{abstract}

Recibido: 17/06/2019. Aprobado: 28/10/2019. 


\title{
Repensando el Estado y la política desde la autonomía indígena: la construcción del Gobierno Territorial Autónomo de la Nación Wampis
}

\section{RESUMEN}

A raíz del conflicto socioambiental de Bagua en 2009 —causado por la ofensiva policial contra los indígenas awajus y wampis que defendían la mantenencia del régimen de derechos colectivos y garantías territoriales- el Perú se convirtió forzosamente en el primer país latinoamericano en promulgar la ley de Consulta Previa (2011). Esto parecía aperturar una vía institucionalizada de la tensa y desigual relación entre el Estado y los pueblos indígenas. No obstante, en 2015 el pueblo wampis apuesta por un camino político divergente al declarar públicamente la articulación del Gobierno Territorial Autónomo de la Nación wampis. Este artículo busca explicar la construcción de esta estrategia de defensa territorial, desde un análisis de la interacción dialéctica entre la estructura de oportunidad política que abre el conflicto de Bagua para el ejercicio del derecho al autogobierno; y la reformulación creativa desde la agencia política wampis, que logra retar la política dentro de los marcos del Estado-nación.

Palabras clave: política rural, movimiento amazónico, autonomía indígena, territorio integral, relación con el Estado, agencia política.

\section{Rethinking State and politics from indigenous autonomy: construction of Autono- mous Territorial Government of Wampis Nation}

\begin{abstract}
In the wake of socio-environmental conflict of Bagua (2009)—caused by police violence against indigenous people (awajun and wampis) who defended their collective rights to land-Perú forcibly became the first latin American country to approve a Prior Consultation Law (2011). This seemed to open an institutionalized path for the turbulent and uneven relationship between State and indigenous communities. Despite this, in 2015 Wampis people positioned a divergent political path by publicly declare the articulation of Territorial Autonomous Government of Wampis Nation (GTANW). This article aims to explain the construction of this strategy of territorial defense, from an analysis of the dialectic interaction between political opportunity structure that Bagua conflict opens for the right to self-government; and creative reformulation of wampis political agency that manages to challenge politics inside the State-nations boundaries.
\end{abstract}

Keywords: rural policy, Amazon movement, indigenous autonomy, integral territory, relationship with the State, political agency. 


\section{INTRODUCCIÓN}

El conflicto socioambiental en la Curva del Diablo (Bagua, Amazonas) en 2009 - causado por la ofensiva policial contra los indígenas awajun y wampis que defendían la mantenencia del régimen de derechos colectivos y garantías territoriales que el Ejecutivo buscaba arrebatarles - llevó a que el Gobierno peruano forzosamente se convierta en el primer país en aprobar una legislación sobre el derecho a la consulta previa (2011). Esto parecía abrir una nueva etapa que permitiría que la conflictividad en torno a los proyectos de inversión se encausaría en un mecanismo institucional de consulta entre el Estado y los pueblos indígenas. Tres años después (2015) en la comunidad de Soledad (Río Santiago, Amazonas) la asamblea de comunidades wampis (protagonistas del conflicto en Bagua) dio un giro distinto al desarrollo de esta historia, al declarar públicamente la creación del Gobierno Territorial Autónomo de la Nación Wampis (GTANW), reivindicando un territorio integral situado en las cuencas de los ríos Santiago y Morona, en el distrito de Río Santiago, en la provincia de Condorcanqui, Amazonas; y en el distrito de Morona, en la provincia de Datem del Marañón, Loreto.

Un gobierno territorial indígena no implica la escisión del territorio peruano, sino el ejercicio del autogobierno indígena sin tener que esperar la legalización del Estado, acto amparado en los derechos territoriales de posesión ancestral (anterior a la constitución del Estado peruano) legitimados por la legislación internacional (convenio 169 de la OIT y la Declaración de las Naciones Unidas sobre los pueblos indígenas). Desde el auge de la política en torno a la identidad indígena desde 1990, los actores indígenas se han constituido como sujetos políticos con una agenda propia y una organización trasnacional (Brysk, 2000) que no solo busca incorporarse dentro del Estado, sino que buscan debatir su misma constitución colonial y liberal (De Sousa, 2004) incapaz de reconocerlos como entidades étnicas con derechos colectivos, distintos al ciudadano individual. Dentro de esta agenda de descolonización del Estado, la autonomía indígena —entendida como el autogobierno por medio de instituciones políticas, sociales y culturas propias - pasó a ser una demanda específica, así como un nuevo paradigma de lucha (Diaz Polanco, 1992) en la década de $1990^{1}$. Esta implica la reformulación de los marcos normativos nacionales e internacionales para acoger sus derechos de autogobierno territorial. De esta forma, esta estrategia de defensa territorial rompe con la dicotomía de la «toma del Estado» y la acción colectiva contenciosa, porque permite el ejercicio del poder político desde la esfera de lo "público social», distinto al poder público estatal o al privado social (Quijano, 1980).

\footnotetext{
1 Existieron tempranos arreglos legales de reconocimiento del territorio indígena en Panamá (1972) y Nicaragua (1982), pero en la década de 1990 el tema se posiciona en la agenda pública de los pueblos indígenas (Gonzales y González, 2015, p. 13).
} 
Para entender la construcción del primer gobierno territorial autónomo en el Perú, consideramos que es crucial debatir los lentes analíticos que estudian la historia de la relación entre el Estado y los pueblos indígenas. La estructura de oportunidad política que se articula en torno al movimiento amazónico en 2009 es crucial para entender las ventanas políticas que se abren para el ejercicio del autogobierno. No obstante, la autonomía (como estrategia política y organizativa) debe ser entendida desde una interrelación dialéctica entre una estructura que se impone y los procesos intersubjetivos de la política indígena que — desde sus sistemas de vida y el aprendizaje intercultural — la van dotando de nuevos sentidos para poder transformarla.

El artículo busca abordar este proceso con las siguientes partes: 1) Los antecedentes de la organización política con fines autonómicos (S. XVI-1990), 2) Bagua como un punto de inflexión de crisis y oportunidades del proceso político (2009) y 3) la construcción del GTANW (territorio integral, nación wampis y estructura organizativa) desde la creatividad política indígena (2009-2015).

\section{1. ¿CÓMO ABORDAR LOS FACTORES QUE EXPLICAN LA APARICIÓN DE LA AUTONOMÍA INDÍGENA WAMPIS?}

En primer lugar, es prominente en la literatura el análisis comparativo de Van Cott (2001) que explica la estructura de oportunidad política (EOP) que permite la aparición de los regímenes autonómicos (autonomías que logra un reconocimiento constitucional) como Nicaragua, Panamá, Colombia, Ecuador y Venezuela. Ella plantea que contextos de grave crisis política y reconfiguración constitucional abren espacios de negociación del tipo de régimen estatal, que permiten a los partidos políticos «étnicos» legalizar sus demandas de autonomía. Aunque los beneficios de ganar el reconocimiento formal al ejercicio de la autonomía son innegables (Gonzales y González, 2015), consideramos que esta aproximación es problemática porque establece una clasificación a priori del éxito político desde la perspectiva del Estado, que es el que define lo políticamente posible. Este criterio contrasta con la gran diversidad de orígenes, de tipos de relación con el Estado y estructuras de las autonomías indígenas en América Latina ${ }^{2}$, que más bien muestran una imagen pluriversal (Delgado, 2015,

\footnotetext{
2 Podemos establecer distintos tipos de autonomías indígenas en América Latina, desde la relación que establecen con sus Estados-nación. Estos pueden contar con reconocimiento dentro de la institucionalidad estatal. En este grupo, encontramos tanto el establecimiento de nuevas jurisdicciones territoriales (autonomías regionales multiétnicas de Nicaragua creadas en 1987, resguardos en Colombia en 1991, autonomías indígenas originarias campesinas en Bolivia e 2009, regiones descentralizadas autonómicas de Ecuador en 2008) como el establecimiento de autonomías a través de legislación ordinaria (comarcas indígenas en Panamá en 1972, territorios indígenas de Venezuela en 1991). En segundo lugar, existen autonomías «de facto» que no plantean como estrategia política el ser reconocidos por
} 
p. 147) y polisémica del fenómeno en América Latina (González y Burguete Cal y Mayor, 2010, pp. 9-20).

Este es el mismo razonamiento que lleva a algunos estudios a caracterizar la política indígena peruana como un "caso fallido" por su incapacidad de articular movimientos nacionales que puedan acceder al poder estatal (Yashar, 2005; Van Cott, 2001). Esto debido a sus débiles movimientos indígenas con dificultades para armar alianzas con el resto del movimiento popular, fuertemente influenciados por la predominancia de líderes carismáticos y que refuerzan relaciones clientelares de representación (Paredes, 2010, p. 237). Aunque se reconoce las dificultades comparativas de la política indígena peruana, esta aproximación no permite ver las distintas formas en los que la política indígena puede expresarse (Lucero, 2008), como los inusuales casos de las rondas campesinas o el movimiento amazónico en relación con la escena política indígena nacional (Paredes, 2010, p. 237).

Por otro lado, desde los estudios antropológicos anarquistas que tienen como punto de partida los pueblos indígenas, la propuesta de Pierre Clastres (1974) de la fórmula de «la sociedad contra el Estado» busca entender la tendencia centrífuga de la sociedad indígena guayaki (Paraguay) para evitar la concentración de poder (aparición de un Estado). Siguiendo este planteamiento, James Scott en The Art of not being governed plantea que los pueblos autogobernados de Zomia (Sudeste asiático) son capaces de escapar a la injerencia del Estado por medio de la adaptación de instituciones elegidas por los mismos sujetos que logra ser ilegibles a los códigos estatales, construyendo un «nonstate space» (Scott, 2009, pp. 5-13).

En esta obra de Scott se encuentra un débil desarrollo acerca de las actividades estatales de la zona o las jerarquías internas de Zomia (Abélès y Badaró, 2015), lo que lleva a establecer la agencia «desde abajo» como invariablemente endógena y repeledora del Estado (Brass, 2012, pp. 126-127). Esto, según Modonesi, es parte sustancial de la mirada teórica de la escuela de la subalternidad acerca de la autonomía política: se establece la subalternidad a la vez como una situación de dominación y como la posibilidad de insubordinación del subalterno. Esto suele plantear que el sujeto subalterno es autónomo por naturaleza, pero sin dejar claro cómo llega a insubordinarse (2010, p. 47). ¿Cómo los actores indígenas construyen su insubordinación en un marco político impuesto?

Desde la historia política de autonomías indígenas latinoamericanas se ha buscado abordar la relación dialéctica entre elementos externos e internos delos pueblos indígenas. Algunos estudios abordan el surgimiento de autonomías desde la articulación de las dimensiones de la historia política (estructura de poder local) y la cultural

sus Estados, como los municipios autonómicos zapatistas en 1991 o el GTANW en Perú 2015 (basado parcialmente en González y Burguete Cal y Mayor, 2010). 
(redefinición de las identidades étnicas) (González y Patiño, 2016; Santos y Renard, 2006) ubicando los procesos institucionales de la política regional, estatales y del capitalismo (Cottyn, 2016; Tomic, 2015). Un aspecto crucial de este grupo de estudios es la valoración de la capacidad de agencia indígena, que implica que se reconocerá como importantes los sentidos que va teniendo este paradigma paralos mismos pueblos desde un proceso de transformación de su identidad colectiva y práctica política, a la vez que redefinen la estructura en la que se encuentran inmersos. Esta reflexión está presente también en los estudios de caso tanto de las autonomías dentro de los Estados plurinacionales de Ecuador y Bolivia y el caso celebre de "autonomía de facto» en los municipios autonómicos zapatistas en México. En los primeros se encuentra una constante tensión dentro de la implementación del derecho del autogobierno que debe luchar por no ser subsumida por la lógica liberal de la estructura liberal incapaz de reconocer las lógicas colectivas territoriales (Postero, 2017; Schavelzon, 2012); mientras que en el segundo caso se encuentra un espacio de gestión creativa comunitaria «liberada» de la acción del Estado corporativista mexicano (Delgado, 2015, p. 147; Mora, 2015, p. 103). En esta discusión, el GTANW ofrece un caso muy interesante para pensar la plasticidad (lo políticamente posible) de la relación Estado-pueblos indígenas en la literatura de América Latina, ya que no supone el establecimiento de una zona libre de presencia estatal (como en el caso zapatista) ni la construcción de una autonomía en el seno del Estado-nación (como los casos de los Estados plurinacionales).

Este tipo de aproximaciones van en la misma línea de los aportes del giro ontológico, específicamente los que presentan a los múltiples mundos u ontologías como espacios que se encuentran, afectándose y resignificándose mutuamente (De la Cadena, 2016: Paredes y Li, 2017) lo que nos permiten ahondar en la constante dinámica negociadora de asimilación/negociación e inclusión/exclusión entre el Estado y el mundo indígena (Merino, 2019; Cottyn, 2016).

Consideramos que un aporte central para estos enfoques es el concepto del «acostumbramiento a la indigeneidad» de Shane Greene. El autor plantea que en el encuentro entre los pueblos awajun y los actores externos, estos últimos imponen una identidad de alteridad, el ser indígena: identidad colectiva que es marcada como distinta e inferior. No obstante, esta imposición es asimilada en primera instancia y respondida con un movimiento de creatividad intencional, el acostumbramiento de la imposición externa de la costumbre impuesta. Existe una articulación ante esta nueva situación, que implica un nivel de creatividad y apropiación subversiva de los términos impuestos, a los que se da un nuevo sentido (Greene, 2009, p. 40). Esto supone una ventaja teórica ya que se diferencia analíticamente las dimensiones de dominación externa (la estructura social, desde donde se construye la coyuntura de la EOP), la articulación a la costumbre impuesta (de ser indígena) así como 
la respuesta de creatividad internacional. En vez de una sociedad contra el Estado, tenemos una sociedad que, ante la imposición del Estado, aprende a producir salidas creativas con el material de la estructura que se le impone, sin dejar de expresar su vivencia ontológica.

Dentro de los estudios sobre la política indígena amazónica en Perú, se encuentra un importante un grupo de estudios que explicitan la necesidad de abordar no solo los sistemas de representación y acción política de los propios pueblos, sino también los elementos exógenos que utilizan o deciden descartar, y su interacción con actores nacionales e internacionales (Surallés, Espinosa y Jabin, 2016; Veber y Virtanen, 2017, p. 5; Romio, 2014). Esto permite entender algunas prácticas en donde los pueblos indígenas permiten redefinir los contornos políticos de algunos procesos de consulta previa o instancias de participación para el desarrollo de instrumentos ambientales (Merino, 2019; Leifsen, Gustafsson, Guzman-Gallegos y SchillingVacaflor, 2017).

En la literatura sobre la historia política del pueblo wampis, existen estudios antropológicos que hacen un importante recuento de la construcción de la organización política wampis y awajun —el Consejo Aguaruna Huambisa (CAH) que expresa un nuevo liderazgo político que negocian los conceptos básicos de su visión ancestral con las enseñanzas externas (Romio, 2014), así como los inicios de la propuesta de territorio integral de la Coordinadora Regional de los Pueblos Indígenas de San Lorenzo (Corpi-SL, base regional de la Asociación Interétnica de Desarrollo de la Selva Peruana - Aidesep) aproximándose a las relaciones políticas que se crearon y se modifican entre los awajun y los wampis (Garra y Riol, 2014). Este artículo buscará aportar a estos trabajos al abordar por primera vezla construcción dela estrategia autonómica en los wampis, que data de 2015.

El proceso de articulación de la estrategia de autonomía indígena — práctica de la política indígena que transita entre la exterioridad e interioridad de la política estatal— debe ser entendido tanto desde el proceso de creatividad política intencional que rearticula la relación con el Estado (concepto del acostumbramiento indígena de Greene) así como desde la relación con la estructura de oportunidad política (EOP) que enmarca su aparición. Esto supone atender las relaciones entre las dimensiones de estructura social y agencia política, que se afectan mutuamente (Gráfico 1). De esta forma, planteamos que los constantes límites del marco Estado-nación para entender lo indígena son factores considerables para entender la articulación de una estrategia de autonomía indígena. No obstante, el factor «impulsor» es finalmente la agencia wampis —el proceso de creatividad política que partió del marco de la política estatal para resignificarlo y cambiar su posición dentro de la estructura social o el «patrón de poder» (Quijano, 2005). 


\section{Gráfico 1. Síntesis de los marcos de la estructura de oportunidad política y la teoría del acostumbramiento indígena de Greene para entender la autonomía indígena}

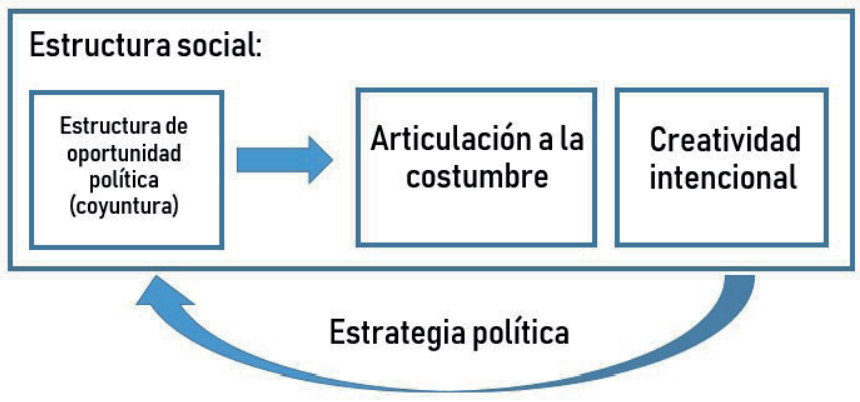

\section{AsPeCtos METODOLÓGICOS}

Esta investigación busca explicar la conformación del Gobierno Territorial Autónomo desde la relación entre los actores externos (en específico, el Estado y aliados políticos) y el pueblo indígena wampis. Esto se realizará por medio rastreo del proceso de un caso de formalización de la estrategia de autonomía indígena wampis, que consiste en encontrar mecanismos causales —enunciados de como intervienen variables y procesos para obtener un resultado especifico — para poder abrir «cajas negras» de procesos sociales (Trampusch y Palier, 2016, p. 442). Para reconstruir este proceso, se recogió información por medio de 24 entrevistas informativas a líderes wampis (y en menor medida a vecinos mestizos y funcionarios de la Municipalidad de Río Santiago) sobre el proceso de construcción del GTANW, así como historias de vida a líderes wampis para comprender la evolución histórica de su relación con el Estado y los aliados políticos, complementando con información bibliográfica sobre el Estado. Fueron realizadas en junio de 2017 en Lima y en dos trabajos de campo al territorio wampis, en junio de 2017 (comunidades de Santiago y Morona) y en noviembre de 2017 en la comunidad de Candungos, Río Santiago ${ }^{3}$. Además, se contó con la revisión de archivos de documentos de reuniones, de acuerdos y otros, archivos de la municipalidad ${ }^{4}$.

\footnotetext{
3 Asimismo, debido a los grandes problemas de accesibilidad, se utilizará una mayor cantidad de información acerca del Río Santiago (en especial, del centro poblado la Poza-Puerto Galilea, lugar más cercano a la ciudad de Nieva en la zona) que la de Río Morona. No obstante, se buscó en lo posible de conseguir información del proceso de articulación del GTANW con entrevistas y dos visitas de campo a ambas cuencas respectivamente.

4 Se ocultó los nombres de los entrevistados — conservando su anonimato- como una forma de cuidado a sus personas. Esta medida se decidió en coordinación representante del GTANW. Se presentan con el rótulo de «entrevistado \#».
} 
En este proceso, es crucial reconocer la importancia de las lecturas políticas de los líderes wampis y sus aliados, que fueron la base para llevar a cabo la investigación. De esta forma, esta investigación no es un «descubrimiento» sobre un proceso causal, sino una sistematización analítica complementaria a una lectura política colectiva por parte de los líderes indígenas wampis que sigue construyéndose.

\section{3. ¿Cómo se Construye el Gobierno Territorial autónomo de la nación WAMPIS?}

El desarrollo de la pregunta se hará de forma cronológica. Primero se abordará la base autonómica de la organización política wampis (S. XVI-1990). Después, se abordará el conflicto socioambiental de Bagua como un punto de inflexión de crisis y oportunidades del proceso político (2009). Posteriormente, se detalla el proceso de creatividad política en relación a tres elementos: el territorio integral, la nación wampis y la estructura organizativa (2009-2015).

\subsection{La organización política indígena como la resignificación autónoma de los marcos externos}

El nacimiento de las organizaciones políticas indígenas de alcance panamazónico (Surallés, 2009, p. 32) deben ser entendidas como parte de la histórica búsqueda de autonomía política y territorial. El pueblo wampis, conocidos como los «indios bravos» e inconquistables desde la época incaica, por medio de constantes levantamientos (Surallés, Riol y Garra, 2017, p. 9) logro evitar su reducción colonial manteniendo un sistema de vida territorial de carácter espiritual, político, cultural y social relativamente autónomo hasta la década de 1950 (Entrevistado 1, 2017; Garra y Riol, 2014, p. 61; Surallés, Riol y Garra, 2017, Pitman et al., 2012, p. 139). En la actualidad, es una de las regiones con más bajos índices de presencia estatal ${ }^{5}$ (Programa de las Naciones Unidas para el Desarrollo, 2013) así como con un alto nivel de conservación ecosistémico, relacionada a la larga historia de protección y adecuado manejo por parte de las comunidades wampis de Morona y Santiago (Pitman et al., 2012). La imposición de un marco de existencia desde el Estado peruano a mediados del siglo XX será respondida por los wampis con un proceso

\footnotetext{
5 En cuanto al índice de densidad estatal, el distrito de Condorcanqui tiene como índice 0,4598, el más bajo de la región de Amazonas $(0,6820)$, que se encuentra en el puesto 20 de 24 de las regiones del Perú. Asimismo, Datem del Marañón $(0,4295)$ también es el más bajo de su región, Loreto $(0,6082)$ que es a su vez la ciudad con menor densidad estatal del país (Programa de las Naciones Unidas para el Desarrollo, 2013).
} 
de apropiación de ciertas herramientas y la creación política creativa (Greene, 2009) en defensa del mantenimiento de su sistema de vida autónomo ${ }^{6}$.

En 1974 la promulgación de la Ley de Comunidades Nativas y de Desarrollo Agrario de las Regiones de Selva y Ceja de Selva (decreto ley 20653) del Gobierno Revolucionario de Velasco reconoce por primera vez los derechos territoriales de los pueblos amazónicos, facultados con la protección y reconocimiento jurídicos, así como a derechos colectivos sobre la tierra por medio del proceso de titulación colectiva (Monterroso, Cronkleton, Pinedo y Larson, 2017, p. 8). Esta política resultó ser reduccionista ya que respondía al uso territorial andino, legalizando a las comunidades en unidades atomizadas de "comunidades nativas» sin ser capaz de captar el uso integral del territorio de la población indígena amazónica (Barclay y Santos Granero, 1980).

Los wampis y awajun, en una alianza interétnica del Alto Marañón, crean el Consejo Aguaruna Huambisa (CAH) en 1977, respondiendo a la tensión territorial creciente (proyectos de colonización agrícola mestiza) que no puede ser defendida con las atomizadoras titulaciones colectivas por comunidad nativa. Esto es logrado en colaboración al apoyo organizativo, formativo y logístico de profesionales externos a la naciente organización de awajun y wampis sobre las implicancias legales de las nuevas leyes que ordenaban su territorio y la necesidad de una organización política. La respuesta política de agruparse en un modelo organizativo de federaciones supone una articulación para obtener más fuerza de representación ante el Estado, ya que se organiza entre pueblos y cuencas (Ballón Aguirre y López, 1987, p. 111) para llenar el vacío existente en la política de titulación de tierras comunales (Greene 2006 en Monterroso et al., 2017, p. 17). Estos procesos de confederaciones políticas a nivel nacional y regional darán lugar a la creación de la Asociación Interétnica de Desarrollo de la Selva Peruana (Aidesep) en 1979 y la Coordinadora de las Organizaciones Indígenas de la Cuenca Amazónica (Coica) en 1984, que muestran la intención política indígena de defender sus demandas desde sus organizaciones, pero apropiándose de los modelos organizativo y lecturas político-legales que aliados externos podían ofrecerles. El marco normativo de existencia que arma el Estado corporativista de Velasco tendrá un paulatino giro neoliberal, enfocado en la promoción de la tenencia territorial individual en desmedro de la propiedad colectiva y del rol ordenador del Estado (Bebbington y Bury, 2010, p. 44) frente al rol preponderante que tendrán los actores económicos globales en la Amazonía a partir de este período (Barclay, Santos, Rodríguez y Valcárcel, 1991, p. 83). La prohibición de la titulación de espacios de bosque (la mayoría del territorio amazónico) que surge con la modificación de la Ley de Comunidades Nativas (1978) (Morel, 2014, p. 29) abre la posibilidad para el cercamiento de las comunidades wampis

\footnotetext{
6 El primer contacto de alta intensidad es la educación formal que llega con los misioneros de ILV, que da lugar a la creación de las primeras comunidades en torno a la escuela (ver Romio, 2014).
} 
por proyectos territoriales tanto de carácter extractivo como de conservación a partir de la década de 2000 (Mapa 1). En el territorio wampis, se experimenta la falta de mecanismos de regulación para la entrada de las actividades de petróleo y minería aurífera en las zonas fronterizas y en algunas comunidades wampis(cuya magnitud es relativamente atenuada) así como el fallido proceso participativo en la Zona Reservada Santiago Comaina (ZRSC) que termina siendo concesionada en 2004 en porcentajes a la Minera Afrodita S.A.Cy a la creación de un área (contra el conceso acordado anteriormente con los pueblos awajun y wampis) (Surallés, Riol y Garra, 2017, p. 40). La superposición de diferentes regulaciones e intereses expresan desde esos años la intensificación de lucha por la gobernanza territorial (Leal, Salisbury, Fernández, Pezo y Silva, 2015, p. 182; García Hierro y Surallés, 2009; Surallés, 2009, p. 32).

\section{Mapa 1. Mapa de superposición de comunidades nativas, áreas naturales protegidas, lotes petroleros y actividad minera en las cuencas de Santiago y Morona}



Fuente: Instituto del Ben Común, 2020.

En esta nueva etapa, sus organizaciones indígenas también pasaron por retos ante el proceso de globalización de la actividad política. El movimiento amazónico mostró tempranamente una facilidad de acceso a las redes de escala global desde 1990 que les permiten trascender el ámbito de lo local y tener un espacio político asociativo capaz de proveer la oportunidad real de organizarse (Breton, 2009, p. 97) que promueve la visibilización de la demanda del territorio desde lo étnico (Chirif, 1997) y no solo desde la clase. No obstante, también implicó el ingreso de una cantidad de inédita de fondos que las organizaciones indígenas no siempre pudieron asumir. Sin dejar de reconocer los logros que tienen Aidesep y Coica en proyectos que buscan el reconocimiento y titulación de las tierras comunales nativas (Greene 2006 en Monterroso 
et al., 2017, p. 14), es importante reconocer que su crisis — más evidente en los años 2000 - estaba en parte relacionada a la falta de seguimiento y control administrativo por parte de los fondos de la cooperación y la falta de experiencia previa en gestión, e innegables casos específicos de interés personal que requieren mayor investigación. Asimismo, su rápido crecimiento en organizaciones regionales hizo más difícil la coordinación entre las bases y los dirigentes nacionales (Chirif, 1997, pp. 155-158).

En el nivel regional, el CAH, que había tenido logros importantes en la protección de derechos indígenas, empezó a mostrar signos de fragmentación en la década de 1980 (Garra y Riol, 2014, p. 63). Finalmente, en 1992 se fragmenta en dos federaciones: 1) la subsede del CAH en la comunidad de Chapiza (Santiago), que les permite autonomía frente a los awajún dentro de la organización del $\mathrm{CAH}$ (Movimiento Regional por la Tierra, 2017, y 2) Fecohrsa (Federación de Comunidades Huambisa del Río Santiago $)^{7}$ en 1994, federación integrada por wampis del Santiago. Las tensiones por la repartición de proyectos entre awajun y wampis, así como los problemas de manejo de fondos de la cooperación internacional (Entrevistado 2, 2017; entrevistado 3,2017) respondían a una dinámica oscilante entre la autonomía local y la integración socioterritorial (Garra y Riol, 2014, p. 63). La presión de gestionar proyectos de forma equitativa en un espacio amplio, así como las limitaciones y desaciertos llevan a la fragmentación de la alianza interétnica.

Es posible que esta crisis política nacional y regional lleve a que una las bases regionales de Aidesep, la Coordinadora Regional de Pueblos Indígena-San Lorenzo (Corpi-SL), decida buscar otro rumbo y trabajar con una agenda propia de territorios integrales, al contrario de la agenda de Aidesep de mantener las titulaciones colectivas ${ }^{8}$. En palabras de un líder de Corpi-SL (Entrevistado 4, 2017) «Corpi empieza a luchar como un huérfano sin padre, pero sigue haciendo hijos, que son los gobiernos territoriales». A inicios de 1995 acompañados de Corpi, los wampis de Oshdem del Morona empiezan a debatir la reconfiguración territorial que debería incluir los territorios de uso y ocupación ancestral, haciendo remembranza y memoria de la ocupación sociohistórica y cultural (Movimiento Regional por la Tierra, 2017). Esta estrategia de territorio integral se basa en la legislación internacional (Convenio 169 de la OIT y Declaración de Naciones Unidas sobre los derechos de los pueblos indígenas) que sustenta el derecho de posesión del territorio anterior a los Estados-nación. Esto obliga al Estado peruano a reconocer el derecho al autogobierno de un territorio integral y no

\footnotetext{
Según Juan Nuningo, se crea en primer lugar Feconarsa (Federación de Comunidades Nativas del río Santiago) como un intento de unificación de comunidades tanto awajun como wampis del Santiago. Pero por tensiones con el CAH, deciden tener una federación únicamente de wampis y cambiar el nombre a Fecorhsa en 1999 (sin fecha).

8 Actualmente, la propuesta de territorios integrales ha empezado a permear en Aidesep (Merino, 2019).
} 
solo unidades comunitarias, aún con las limitaciones de la normativa nacional para poder hacerlo (GTANW, 2017). El manejo de estos marcos legales es posible gracias a largo trabajo colectivo de titulación de comunidades y cartografía social con los antropólogos Alberto Chirif y Alexandre Surallés y el abogado Pedro Garciía Hierro —entre otros- que permite introducir la iniciativa en 1995 (Tuesta, 2015, p. 52). Posteriormente, en 1996 Corpi-SL inicio un debate tanto en las comunidades wampis y otros nueve pueblos de su jurisdicción, en el que se dan los primeros criterios, medidas, estrategias y mecanismos para la recuperación territorial integral o territorialidad. Es decir, la configuración territorial como pueblos (GTANW, s. f.) y no solo como comunidades nativas.

Se empieza a reconocer la dificultad de la organización federativa de hacer frente a los retos de una política globalizada, que llevará a actores como Corpi a apostar por un "giro hacia adentro" para construir una defensa territorial teniendo como base de poder el territorio ocupado por los pueblos, ampliado la ventana de lo políticamente posible. Veremos que el conflicto de Bagua (2009) será un punto de inflexión de estas crisis y nuevas oportunidades para que este proceso iniciado del paradigma de autonomía indígena tenga una arena propicia para su desarrollo.

\subsection{El conflicto de Bagua como punto de inflexión: crisis y oportunidades}

La intensificación progresiva de las tensiones que surgen por la apertura normativa territorial a la posibilidad del despojo de los recursos naturales de la Amazonía se expresa claramente en el conflicto social de 2009 en Bagua (Amazonas) en el contexto de los paros indígenas. En junio de 2008 el Ejecutivo aprueba 99 decretos legislativos para poder cumplir con condiciones básicas para la entrada del comercio internacional en el contexto de la firma del Tratado de Libre Comercio con Estados Unidos (Hugues, 2010; Schamll, 2011 citados en Merino, 2015, p. 88). Ante esto, los pueblos indígenas amazónicos organizados — junto con sus aliados externos- reconocen de forma oportuna en su lectura política que estas medidas amenazan sus derechos de propiedad colectiva (Monterroso et al., 2017, p. 17) aseguradas en el convenio 169- OIT. Esto se logragracias al intercambio de información por medio de tecnología radiofónica, televisión y redes políticas locales entre sus bases (Romio, 2018).

Es importante ubicar este hecho en la historia de largo plazo de la relación con el Estado peruano como una respuesta a la inseguridad territorial producida por el Estado y los actores económicos (Romio, 2018). Este conflicto es entendido desde los pueblos jibaros como una "competencia entre fuerzas de vida" (Brown, 2014 y Santos Granero y Barclay, 2010 citados en Romio, 2018) ya que por un lado se defiende la base ontológica de la vida indígena: el territorio integral, entendido como ensamblajes sociales entre los humanos y los no humanos (Merino, 2015, p. 91; De la Cadena, 2016) y por otro lado la conversión del territorio en mercancía 
globalizable por parte del Estado. De esta forma, Bagua es la extensión de la larga defensa del sistema de vida wampis yawajun.

La defensa de la centralidad del territorio se logra expresar gracias a las redes organizativas que el movimiento amazónico había estado construyendo desde la década de 1970, que permite la organización de los paros amazónicos de 2008 y 2009 por varios meses y de forma masiva, lo que supone un esfuerzo político importante que pocas organizaciones sociales en el Perú podrían mantener (Cavero, 2011, p. 195). A pesar de que varias bases regionales expresan dudas acerca de la efectividad dela protesta en una coyuntura marcada por pugnas internas al interior del Consejo Directivo de Aidesep, la dirigencia respondió al insistente pedido de las bases que rechazaban la política arbitraria del gobierno porque reconocían el peligro que suponía el avance de esas políticas (Chirif, 2012).

El día 9 de agosto Aidesep convoca a un paro indefinido y anunció acciones de lucha contra los decretos promulgados. Ante esto, el 5 de junio de 2009, cientos de indígenas awajun y wampis - en una alianza interétnica - realizaron una protesta en la provincia de Bagua, región Amazonas, para exigir la revocación de los decretos. Un grupo de wampis del Santiago pudieron viajar hasta Bagua para apoyar en la toma de la Estación 6 de Petroperú junto con compañeros awajun, mientras que otros tomaron la ciudad mestiza de Nieva, esperando el diálogo con el Estado. Ante la negativa del Estado a recoger sus demandas, el 5 de junio un grupo de awajun y wampis toman la Estación 6, y son retirados en la Curva del Diablo por las fuerzas policiales ordenadas por el Ejecutivo. Se produjeron enfrentamientos violentos entre los manifestantes indígenas y la policía, que dejaron 33 muertos (Entre indígenas y policías) y 200 heridos, convirtiéndose en un escándalo nacional e internacional. El 19 de junio, dos semanas después de los trágicos acontecimientos de Bagua, el Congreso - contra la voluntad de Alan García (De la Cadena, 2016, p. 254)_ revocó los decretos legislativos 1090 y 1064 y la huelga indígena se levantó luego de tres meses de protestas (Monterroso et al., 2017, p. 17). Heridos, cansados y expectantes de una respuesta digna de su sacrificio, los wampis verían que el producto de este acontecimiento fue una victoria pírrica.

\subsection{1. ¿Qué quedó después de Bagua?}

Los violentos acontecimientos de junio de 2009 — causados por un Estado incapaz de evitar los siniestros resultados-consolidaron el apoyo nacional e internacional a los derechos de pueblos indígenas. El reconocimiento internacional como defensores del bosque y la mayor atención por parte de cooperación internacional, movimientos conservacionistas y centrados en la titulación colectiva que inició en la década de 1990 presionan al Gobierno peruano a abrir un diálogo con las organizaciones indígenas para abordar sus reclamos (Fondo de las Naciones Unidas para la Infancia, 
2009, p. 10; Larson et al., 2017, pp. 5-6). Parecía que después del conflicto, se abría una estructura de oportunidad política orquestada por el Estado e instancias internacionales para poder implementar los derechos colectivos territoriales. No obstante, este conflicto también exacerba puntos complicados dentro de la organización política amazónica y de la relación con el Estado, que llevaría a la necesidad de una reformulación de susestrategias.

Por parte del Estado, para responder a la presión local e internacional luego de la tragedia de Bagua, en coordinación con el recién creado Grupo Nacional de Coordinación para el Desarrollo de los Pueblos Amazónicos, que reúne a diferentes sectores gubernamentales con Aidesep y Conap, promulga la ley de consulta previa (Ley del Derecho a la Consulta Previa a los Pueblos Indígenas u originarios, $\mathrm{N}^{\circ}$ 29885) en agosto de 2011 y su reglamento entre 2011 y 2012. Esta ley estableció disposiciones específicas que exigían que los pueblos indígenas fueran consultados sobre cualquier acción administrativa y legislativa, así como sobre cualquier plan o programa de desarrollo, que pudiera afectar sus derechos, antes de que cualquier acción entrara en vigor (Monterroso et al., 2017, p. 22). Esto es un logro histórico que regula y abre el espacio institucional para el necesario diálogo entre los pueblos indígenas y el Estado.

A pesar de estos importantes logros normativos en materia de participación, la política económica de ese período siguió priorizando la privatización y las inversiones a gran escala, mientras que la Consulta Previa se va mostrando como un mecanismo no imparcial y poco sustancial (Merino, 2019). Para los wampis, la obtención de la ley de Consulta Previa fue una victoria en primera instancia. Con los ańos han ido aprendiendo que el proceso de implementación de la ley es insuficiente para asegurar la seguridad de tenencia de sus territorios, ya que su aplicación no vinculante depende excesivamente del criterio estatal y su agenda extractiva. Los lotes petroleros otorgados a las empresas en la Amazonía entre 1995 y 2011 no han sido sometidos a procesos de consulta previa (Vega, 20 de agosto de 2018). La concesión del lote petrolero 64 en 1995 a Atlantic Richfield Perú Inc. (ARCO) no pasó por un proceso de Consulta Previa por parte del Estado a pesar de la vigencia del convenio 169-OIT y de la constante insistencia de los pueblos achuar y wampis (Chirif y Barclay, 2019, pp. 15-17). Asimismo, el lote 116, concesionado en 2006 a Hocol Peru SAC tampoco ha pasado por un proceso de consulta con estos pueblos. Por medio de las experiencias propias y ajenas, desarrollan una lectura general del funcionamiento del mecanismo. Los wampis enfatizan la incapacidad del mecanismo de no reconocer el consenso como central en el diálogo con los pueblos indígenas:

Acá nadie puede ir el contra del Estado si viene a consultar para la actividad. Pero [el Estado] hace actividad y después hace consulta. Es al revés su política. No sirve mucho. La ley de consulta previa es un elefante blanco, porque sin ley o con ley, el convenio 169 es más claro que la propia consulta, es un saludo a la bandera. 
El artículo 15 es clarísimo: si el pueblo se niega a hacer un negocio con la empresa extractiva a través de la consulta, el gobierno es el que toma las decisiones finales. ¿Para qué tengo ley si no van a respetar lo que yo digo? (Entrevistado 5, 2017)

Se concluye que el proceso de la consulta previa más que una consulta es un procedimiento de convencimiento en donde el Estado busca atacar las debilidades de la organización: Aprenden que esta ley como «un juego del Estado. Un «enamoramiento» [...] porque te siguen consultado hasta que te convencen» (Entrevistado 4, 2017).

Los productos positivos del Baguazo fueron perdiendo interés y confianza por parte de los wampis, que iban conociendo la incapacidad del Estado peruano de reconocer sus derechos colectivos en su marco de existencia político. De esta forma, los avances en normativas de participación y autodeterminación indígena se ven limitados por la política económica en torno a los recursos naturales. No se deja de exigir el mecanismo de consulta previa, pero se fue clarificando que era insuficiente, lo que exige la búsqueda de otras salidas políticas.

Asimismo, otro efecto importante del Baguazo fue la reconfiguración política que sufre la organización indígena awajun y wampis. La criminalización de los dirigentes que hacen uso de su derecho a la protesta social en los conflictos socioambientales lleva al descabezamiento del movimiento amazónico que ya se encontraba en una crisis dirigencial (Garra y Riol, 2014, p. 64). Pocos dirigentes awajun y wampis de las bases regionales se mantienen en sus posiciones ya que eran perseguidos y algunos procesados judicialmente con amenaza de cadena perpetua, por lo cual no podían salir de sus comunidades. El entrevistado 5 dibuja este contexto sombrío:

Después de que regresamos a las comunidades sentimos todo perdido. El encarcelamiento, persecuciones con fuerza. ¿Qué íbamos a hacer? El Estado ya nos tenía presionados a través del Ejército, tenía tildados a dirigentes. Los awajun ywampis se quedaron sin fuerza política. Pizango se había escapado a Nicaragua como perseguido político, y nos abandonó. No había ningún dirigente que saliera (2017).

Aunque existía la posibilidad de que el CEPAW (Consejo Especial Permanente de los Pueblos Indígenas Awajun y Wampis) —una comisión ad hoc creada con el pueblo awajun para poder defender en conjunto sus derechos colectivos y acompañar a los enjuiciados con líderes no perseguidos (Entrevistado 2, 2017) — pueda lograr rearmar la alianza interétnica, los constantes intentos de divisionismo por parte del Estado, Petroperú o mineros ilegales afecta la unidad de algunas bases awajun, lo que lleva a que los wampis decidan dejar la alianza interétnica momentánea (Entrevistado 5, 2017) 9 .

\footnotetext{
9 No obstante, queda pendiente obtener mayores datos acerca de la perspectiva awajún sobre este proceso.
} 
La valentía wampis y awajun pudo traer atención nacional e internacional a sus luchas, pero al mismo tiempo costo bastante caro en términos de vidas humanas y represión estatal. Para los wampis, que dejan nuevamente la alianza interétnica al dar cuenta de la debilidad del modelo de federaciones y de alianzas regionales, este conflicto supondrá la necesidad de reformular sus estrategias políticas para continuar la defensa del territorio alrededor de la cordillera de Kampankis.

\subsubsection{El proceso de unidad étnica}

Otra de las consecuencias del conflicto de Bagua fue la intensificación del proceso de politización de la identidad étnica como centro de la acción política wampis. Como indicamos anteriormente, Corpi-SL había empezado en 1996 el proceso de difusión de la estrategia de territorio integral con los pueblos de su jurisdicción (GTANW, s.f.). A partir de Bagua, los cooperantes extranjeros y las organizaciones indígenas convergen en la necesidad de asegurar la seguridad territorial de los pueblos indígenas, lo que arma una arena propicia para la propuesta de Corpi-SL. El trabajo a partir de herramientas diversas que abordan la importancia ecológica, cultural y política del territorio realizada por universidades, ONG, cooperación internacional empieza a difundirse con más fuerza. En el caso de los wampis, se inicia un mapeo colectivo de la vivencia territorial del pueblo wampis, como una forma de establecer una zonificación propia para sustentar el derecho de estos a sus territorios amparados en la legislación internacional que reconoce el derecho al autogobierno de un territorio ancestral. Para esto, Corpi-SL y diferentes aliados propician encuentros de las federaciones de los wampis del Santiago, ofreciendo nuevos marcos de acción política. Como indica el entrevistado 3 (2017):

En Galilea nos reunimos con personas clave sobre defensa territorial y convenio 169. Dicen que ahorita [después de Bagua] es momento oportuno, aprovechemos y tratemos de unirnos. Es oportuno porque nunca hubo oportunidad. Y de un momento a otro ONU trabaja a favor de comunidades y nos da convenio. Convenio 169 es muy favorable. Teníamos buenas relaciones con SAIPE, eso nos fortalece.

La posibilidad de alianzas con aliados fortalecidos a nivel internacional y la promoción de nuevas fuentes de sustento legal para sus derechos colectivo es parte del contexto pos Bagua. En 2009 — meses después del Baguazo— se promueve el primer trabajo de campo para sustentar la vivencia ancestral del pueblo wampis (GTANW, s.f.). Además, antes y durantelos paros amazónicos el Field Museum de Chicago había empezado un informe biológico y social de los cerros Kampankis, en colaboración con el Instituto del Bien Común y Corpi-SL. Este proyecto, al inicio pensado por algunos wampis como un intento de extranjeros de mapear las riquezas para extraer en su territorio, después de un diálogo, finalmente es aprobado por las comunidades. 
Es un importante intento por mostrar de forma «científica» el excelente nivel de conservación del Cerro Kampankis y el mérito de los pueblos wampis al haber producido esta conservación en su interacción con el entorno ecológico, debido a un conocimiento detallado sobre el complejo ecosistema de Kampankis acumulado por cientos de años. La información recopilada gracias a sus aliados científicos permite que los wampis reconozcan y revaloren estos elementos en la construcción de su identidad:

De allí empezamos a hablar de cordillera Kampankis. Esa cordillera es riquísima, tiene de todo. Como pueblo wampis hemos dicho: nuestros ancestros vivían allí, ese es territorio ancestral, histórico, donde nuestros antepasados han conservado biodiversidad, no lo ha depredado, lo ha mantenido, cuidado, preservado. El monte es fuente de la vida de nuestros antepasados es una herencia antes de conquista y antes de confirmación del país. Por lo tanto, por derecho y por ley eso nos corresponde a nosotros (Entrevistado 2, 2017).

En este proceso se encuentran los líderes de Fecohrsa y de la subsede del CAH (Opivac). Como indicamos anteriormente, estos se encontraban enfrentados en torno a la alianza interétnica con los awajún. Estos nuevos marcos de referencia que legitiman su uso territorial y su especificidad como pueblos indígenas propicia el acercamiento de los líderes en disputa. Como cuenta un líder de Candungos (Entrevistado 6, 2017):

En la creación del estudio biológico [del Field Museum] ya se llega a realidad [la idea de la unidad]. Allí ellos [los líderes de OPIVACy FECORSA] se unen. Ya no era mentira. Se involucran, conversan entre ellos. Queríamos avanzar y que la gente se convenza. Llegan a entender muy bien, vamos a trabajar juntos. Porque el trabajo es de un pueblo.

De esta forma, la articulación en una unidad hacia un gobierno autónomo les permite tener mayor impacto político en las comunidades, lo que ya no permitía el modelo federativo fragmentario ni las instancias del Estado. Como indica el entrevistado 7:

Funciona mejor que una federación. Abarca dos cuencas, por eso funciona mejor. En la municipalidad es del Estado, dependes de él. El gobierno autónomo te da más libertad. El Estado casi no respeta porque somos organización pequeña, como FECOHRSA, formada por comunidades, y casi no tiene peso para enfrentar a un gobierno. La idea era construir una casa más grande, con dos cuencas hacer una sola fuerza. Para enfrentar petroleras y madereras, tienen idea ellos también y coincide (2017).

El entrevistado 4 (2017) cuenta que tomaron varias reuniones, encuentros causales y pactados en Nieva, en Galilea, en talleres y eventos, para que los lideres wampis de Fecohrsa y la subsede (OPIVAC) empiecen a reconocer la importancia 
de dejar sus diferencias y centralizar las cabezas de decisión política, ante un fuerte enemigo común. No obstante, el paso hacia una estrategia que vaya «más allá» del marco estatal implicó la introducción mucho más evidente de su propia ontología a sus estrategias políticas, como se detallará.

\subsection{La autonomía indígena: construcción híbrida del poder territorial}

La creciente inseguridad territorial y la imposibilidad de encontrar soluciones dentro de los marcos estatales y en las fragmentadas federaciones ponen al pueblo wampis en un dilema acerca de cómo plantear la estrategia de defensa territorial. El marco de reconocimiento internacional a los derechos de autogobierno - manejados gracias al acompańamiento empoderador de sus aliados externos- es una base para la legitimación de la autonomía indígena. Pero es crucial tomar en cuenta que el GTANW como estrategia es producto del contenido articulado por los líderes wampis. Esto implica un movimiento de creatividad política que conecta la defensa de un sistema de vida con una lectura crítica del Estado, produciendo un concepto híbrido del territorio integral.

Desde mediados de la década de 1970, los wampis han tejido redes de apoyo interculturales con aliados externos que llegan a su territorio. El caso de Pedro García Hierro "Perico», un personaje crucial en la historia política de los pueblos jibaros y amazónicos en general, es muy ilustrativa de la forma en la que se daba el interaprendizaje —encuentro de dos mundos ontológicos - de los aliados externos y los líderes indígenas. Existen registros de compañeros de trabajo, así como de líderes indígenas que comentan que gracias a su íntima convivencia con las comunidades awajun, él llega a comprender la centralidad del territorio en la vida indígena, que lo lleva a apoyar la creación de las primeras organizaciones indígenas. Como abogado, ofrece talleres sobre los cambios de las «reglas de juego» legales sobre tierras comunales en el giro neoliberal del Estado, así como las nuevas ventanas de oportunidad creadas desde la legislación internacional acerca de los derechos indígenas. En 1993 y en 2007 el Perú ratifica el Convenio 169 de la OIT y la Declaración de las Naciones Unidas sobre pueblos indígenas, que abre la posibilidad de una base legal para el reconocimiento del derecho territorial sin pasar por instancias nacionales. La enseñanza de estos contenidos legales es promovida por él buscando el empoderamiento indígena, "como un gato de Chesire que disfruta borrándose a sí mismo del escenario» (Tuesta, 2015, pp. 103-103).

Un aspecto crucial a considerar es que el trabajo de empoderamiento de Garcia Hierro se daba en base al aprendizaje del mundo ontológico wampis, por medio de los sabios. Ellos, nacidos antes de la conformación de las comunidades desde el Estado, son conocedores de la conexión espiritual, material y social de los wampis con el espacio habitado. Asimismo, han ido acumulando experiencia política en el CAH y en experiencias como en la Municipalidad de Río Santiago. Gracias a ellos, se logra 
transmitir el contraste entre el territorio como «una vivencia única que han podido traspasar por siglos, sabiduría de los viejos que iban al monte a conocerlo con el espíritu, a sentirse uno solo con él» (Entrevistado 3, 2017) siendo la base de la supervivencia física y cultural de los pueblos indígenas (Riol, 2015, p. 55), en contraste con la idea de territorio desde códigos legales occidentales.

Ellos van comprendiendo que la legalización de su tenencia territorial ante el Estado - la principal estrategia de defensa territorial — pasa a ser parte de la «trampa del Estado" ya que es utilizada por algunos actores para lucrar con la división territorial. Concluyen que la política de titulación colectiva ayuda a la fragmentación territorial y deciden desistir de ella:

Hay otros intereses de algunas comunidades. Los engañan y es fácil que caigan. El Banco Mundial ha pensado: ¿Cómo divido a los pueblos indígenas y los parcelo para nosotros ser los dueños? Ellos invierten plata en los Estados. Dice «yo les ayudo a titular tierras de comunidades. ¿Qué pasa con los «espacios en blanco»? No le pediremos al Estado de rodillas para no caer en la trampa. [...] No necesitamos una ley para el territorio integral. Trampa del Estado es tener documento o no. Pero no vivo aquí antes que tú. Si hay suficientes normas que lo reconocen. [...] Estamos coordinando para que no haya nuevas titulaciones, solo las que van 15 años esperando. Quienes quieren titularse, no es para defender su territorio. Ellos están a favor de la empresa. (Entrevistado 5, 2017).

De esta forma, el Estado mira al espacio amazónico como un objeto (existente solo en el papel) que es utilizado para su beneficio económico, independientemente de las consecuencias sociales y ambientales. En cambio, el GTANW —como expresión del pueblo wampis - parte de una visión territorial que reconoce la interdependencia de lo humano y no humano en el espacio amazónico (Entrevistado 5, 2017). Se reconoce que los wampis no son «contenedores vacíos» de contenidos externos sino actores activos que leen políticamente su ontología territorial, así como la del Estado. Esta lectura crítica del Estado no lleva a la conclusión de exigir una mejor presencia estatal, sino que es llevada más allá, hacia otro entendimiento de lo políticamente posible para ellos. Se entiende que esto no es una cuestión temporal, sino que ha sido parte de la constitución misma del Estado desde sus inicios. Por eso, el camino hacia la autonomía es entendido como un camino de libertad e independencia de la relación desigual que se establece con la constitución del Estado-nación. Un dirigente de la comunidad de Boca Chinganaza dijo lo siguiente en una asamblea wampis:

El GTANW es conseguir independencia, es la libertad para nosotros. La independencia, del 28 de julio de 1821, no ha sido para nosotros, ha sido para los mestizos. La República nos ha explotado, ha violado a las mujeres. Recuerden la era del caucho por los colonos. Ahora el Estado no reconoce la existencia, no respeta el convenio 169. El Estado no nos puede limitar (Entrevistado 7, 2017) 
La cristalización de esta lectura crítica al Estado se logra al empalmarse con los marcos legales internacionales a los que pueden tener acceso gracias a sus aliados en ONG. La autonomía indígena es asimilada con mayor facilidad ya que no implica una ruptura con el orden legal — que han usado políticamente desde la década de 1970 y con el cual tienen cierta familiaridad - sino que es una reinterpretación/ apropiación de este para la ejecución de derechos ya otorgados. No obstante, aún con el sustento legal que los marcos internacionales ofrecían a esta propuesta, es sumamente problemática para el Estado y para algunos abogados (e inicialmente para algunos wampis que no la comprendían), ya que requería pensar la política fuera de un marco de participación delimitada por el Estado-nación, en donde el poder se accede por medio de canales institucionales a nivel nacional. Gracias a las redes del movimiento indígena mundial, su balance de los límites del proyecto autonómico boliviano - dentro del seno del Estado-nación - les permite afianzar la idea de la necesidad de una construcción social e institucional de un gobierno propio desde lo local, que el Estado no puede ni quiere asegurarles (Entrevistado 5, 2017).

Además, en esta estrategia se va reconociendo que el poder no se "toma» sino que se construye desde la articulación de la unidad étnica. Es una estrategia que requería valentía y confianza sobre su capacidad de gobernar. La apelación a una dimensión espiritual que dota de fuerza la acción política. Como expresa el entrevistado 4:

Es inconstitucional para su mente [de los occidentales]. Ellos no tienen visión de a dónde queremos llegar. Ustedes son profesionales, por eso hablan así. Copiado del apach [occidental], de la universidad que te engañó. Solo les explican teóricamente. Ellos defienden otros intereses. Los gobiernos autónomos no son «organización», tienen el mismo rango que PPK. ¿Por qué queremos llegar a ese nivel? Porque todos los recursos los siguen saqueando. Acaso no tenemos sabiduría, capacidad. El Perú es unitario, wampis también es unitario. Debemos llegar a ese nivel. Vendrán a joder de dentro y fuera. Por la plata caemos en un error. Trabajo es complejo y amplio. Este camino es lo mejor para llegar a visión que sońaron los ancestros (2017).

La noción de la visión que menciona es central para entender el proceso intersubjetivo y espiritual de articulación de la autonomía wampis. La visión es un concepto central en la jerarquía de poder político y espiritual en los jibaros (wampis y awajun) en contextos de enfrentamientos militares. La aspiración de cada joven era acceder al estatus de waemaku, es decir un "guerrero visionario" por medio del contacto con seres espirituales poderosos cuyas palabras y gestos dan información sobre su futuro y deberes en la sociedad, es decir, la obtención de la visión. Esto ocurría por medio de una preparación física y espiritual mediante los rituales de ayahuasca y otros alucinógenos. Crucial era poner en acción la visión obtenida que en su mayoría era la matanza del enemigo, que pocos lograban (Romio, 2014, pp. 144-145). En el 
discurso político wampis está constantemente presente el uso de la visión como la imagen espiritual que las personas buscan lograr en su vida, tanto sus motivaciones como forma de ver el mundo que buscan aplicar. El GTANW parece ser la materialización de las visiones espirituales de los ancestros wampis.

Basándose en este conocimiento corporalizado en los sabios wampis y con el trabajo conjunto con abogados como García Hierro, que pueden entender la forma de vida jíbara, se logra conceptualizar al sistema de vida wampis como territorio integral (Entrevistado 1, 2017), que parte de un sistema de vida autónomo defendido, dotado con la fuerza de la visión espiritual del guerrero, y articulado con una lectura crítica de los límites del Estado. Todo esto enmarcado en un marco de existencia ampliado por la legislación internacional. Es un gobierno indígena que arma su propio marco de existencia. Este proceso se puede ver materializado en la siguiente imagen, que es un mapa histórico y cultural elaborado en base a talleres con comunidades wampis, en conjunto con antropólogos aliados, para reflejar la complejidad de la vivencia territorial de los wampis. En este, se indican dimensiones del territorio como el espacio como vínculo espiritual, como sustento material y las huellas históricas del tiempo que han vivido allí y que les da la identidad (GTANW, s.f.) (Imagen 1).

De esta forma, podemos ver que las nociones de territorio integral que empiezan a ser parte de las estrategias de los wampis son clave para entender su proceso de politización de su etnicidad, es decir, del proceso por el cual la identidad étnica empieza a adquirir centralidad en la esfera política. A pesar de que muchos estudios pueden concluir en que los casos de politización étnica en el Perú tienen el peligro de tratarse de reivindicaciones culturalistas sin implicancias para el contenido político (Cavero, 2011, p. 214) vemos en este caso que lo étnico adquiere una estrategia que no solo apela a la identidad por su potencia política, sino por el contenido y la fuerza espiritual que esta aporta para la gestión adecuada del territorio amazónico, en contraposición con la fallida gestión estatal.

Para 2011 empiezan las conversaciones formales para la construcción de un territorio integral por medio de un gobierno autónomo. En ese año, Corpi-SL obtiene un importante financiamiento para construir territorios integrales gracias a la cooperación internacional, cuyo plan buscaba abarcar tres pueblos indígenas, construyendo los primeros gobiernos autónomos del Perú. Debido a problemas de uso indebido de fondos de otro pueblo indígena que estaba "primer en la lista", Corpi-SL decide continuar con la construcción del gobierno autónomo con los wampis, al ver la experiencia política y técnica de sus principales líderes (Entrevistado 4, 2017). 


\section{Imagen 1. Detalle del mapa histórico y cultural del GTA}

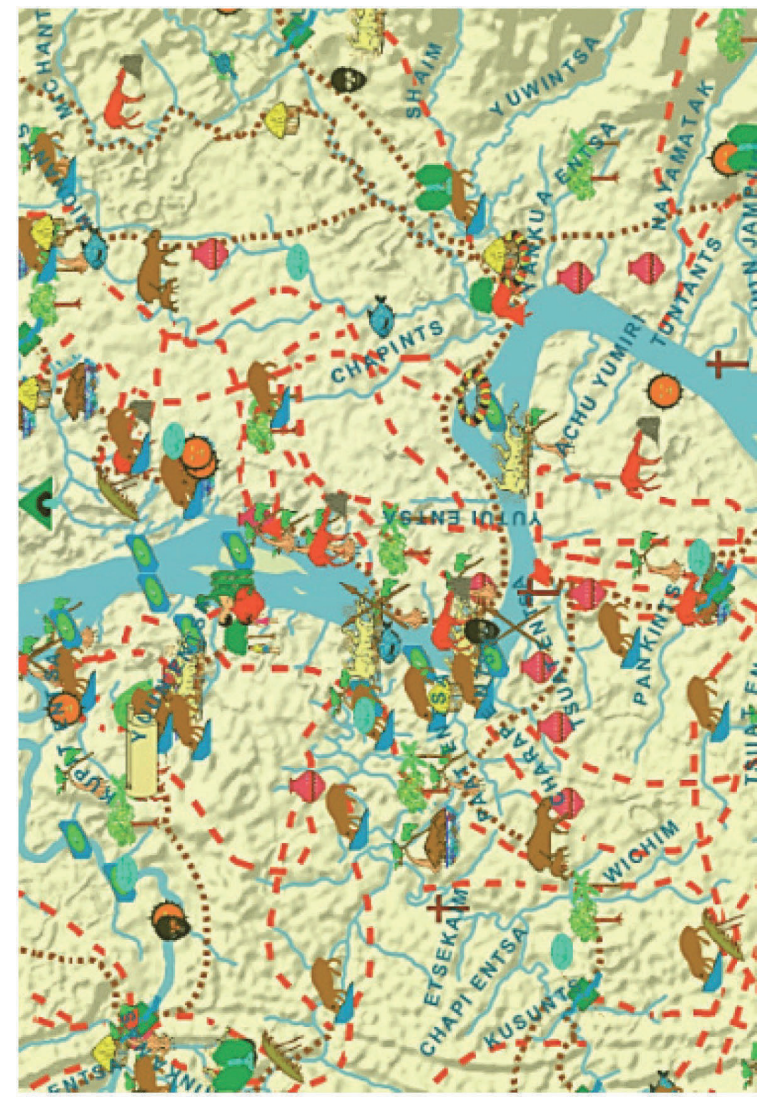

Fuente: Surallés, Riol y Garra, 2017.

\subsection{Nación y estructura organizativa}

Vemos que con el inicio del trabajo unitario de los wampis del Santiago - anteriormente organizados en dos federaciones - se empieza el proceso de articulación del GTANW. Un paso inicial es la elaboración de un informe jurídico y antropológico, para justificar su identidad indígena y posesión ancestral del territorio, logrados gracias a colaboradores de ONG y de la cooperación internacional ${ }^{10}$. Esto les permite contar con los estudios para sustentar la estrategia de autonomía wampis ante los aliados externos y el Estado. No obstante, en el caso de los wampis la apuesta autonómica implicó sobre todo la articulación «de base» entre cuencas (Santiago y Morona) y comunidades, convirtiéndose en el corazón del modelo autonómico.

10 Centro de Políticas Públicas y Derechos Humanos-Perú Equidad, Program Forest Peoples (FPP) y Global Greengrants Fund (GGF). 
Fue necesario emprender la «socialización» que implica un proceso de transmisión y discusión de la propuesta basada en la difusión de los derechos de autogobierno reconocidos internacionalmente, información que las comunidades (sobre todo del Morona) difícilmente tenían acceso. Es interesante notar que este proceso implico ofrecer ejemplos prácticos de la situación de otros pueblos indígenas para que pudieran entender la importancia de la autonomía:

No nos conocíamos con los de OSHDEM. Nos hemos unido con Morona en 2011, 2012, 2010, empiezan coordinaciones. Había mentalidad de conformar nación wampis. Primero fue la visita de los dirigentes del Río Santiago, entran por Morona, comunidad por comunidad hacen consulta, dando a conocer los derechos de los pueblos indígenas en convenio 169, convenio de la ONU y otros tratados. Muchos del Morona no conocían estos. ¿Quién les va a dar orientación, taller, si ellos no tenían fondo ni iniciativa? Mientras que en Río Santiago a través de SAIPE y ONG que ya conocían esto se daba. Al conocer esto ya se transmite a Morona, conversando poco a poco, explicaron que queremos conformar organización grande: tanto Santiago y Morona en defensa de Cordillera de Kampankis. Si no, empresas a través de coordinaciones con el Estado van a empezar a explotar oro, petróleo, gas madera. Vamos a seguir siendo peones de ellos, el territorio va a ser de ellos. ¿Y nosotros siendo propietarios de nuestro terreno vamos a dejar? Va a pasar carretera binacional, y nosotros no nos vamos a beneficiar, son intereses de grandes empresas transnacionales. Poniendo ejemplos, la gente entendía que si había que organizarse (Entrevistado 2, 2017)

Esto también implicó un proceso de reconocimiento de que las cuencas del Morona y Santiago pertenecen al mismo grupo étnico, que es una familia que pasa por problemas similares. A partir de esta identificación de wampis del Santiago y Morona como parte de un «nosotros» (un grupo étnico) se pudo resignificar la categoría «nación» cuya base es el territorio que identifican y reclaman como suyo, superando la atomización comunal: «Desde allí hemos pintado en nuestros cuadernos, trabajado, que debemos conformar nación wampis. No es país, es nacionalidades de los pueblos indígenas, es conjunto de pueblos originarios amazónicos» (Entrevistado 2, 2017).

A la par, desde 2014 hasta 2015 se construye un Estatuto del GTANW, como la estructura que ordenaría distintas dimensiones de la vida de las comunidades wampis, en colaboración con aliados abogados: «El estatuto se hizo en más de 12 talleres, con la estructura y los derechos. No había una propuesta previa, se construye de cero [...] Cuando van discutiendo en asamblea, el que le da cuerpo jurídico es el doctor Perico [Pedro García Hierro]» (Entrevistado 5, 2017). La formación del estatuto se realiza con ayuda del abogado Perico y es presentado en las comunidades de Santiago y Morona para la socialización. Las cuatro instancias de gobierno que se establecen (asamblea principal, Ejecutivo, gobiernos de cuenca y gobiernos de comunidades nativas) establece una rotación de poder entre los gobiernos de 
cuenca (constituidos por las antiguas federaciones) (Entrevistado 7, 2017), así como el mantenimiento de un nivel de autonomía comunal, siendo estas las principales instancias de decisión. De esta forma, este proceso no implica la concentración de la autoridad en unos pocos, sino una confederación de grupos relativamente autónomos y organizados (Garra y Riol, 2014, p. 68) que interpelan constantemente a sus representantes centrales elegidos. No es un modelo clásico de «centralización del poder» de la democracia representativa liberal en donde los ciudadanos ceden su capacidad de decisión, sino un modelo más fluido que reconoce la autonomía política de las comunidades y las cuencas. Se construye una relativa centralidad para enfrentarla inmersión de flujos globales, sostenida sobre una dinámica política interna que no se disuelve en lo representativo (Imagen 2).

Imagen 2. Pamuk (presidente) juramentando ante una mujer asambleísta



Fuente: Elena Campos y GTANW.

Asimismo, los artículos 35, 36 y 37 del Estatuto establece que ninguna empresa extractivalegal o ilegal puede realizar actividades en el territorio wampis sin un proceso de consulta previa con estándares de calidad, o antes de que termine el proceso. De lo contrario, se considerará sin validez cualquier trato efectuado a favor de la empresa. Sin rechazar las ventajas que ciertos procedimientos estatales les pueden brindar, deciden utilizarlos y complementarlos debido a su limitación de no considerar el consentimiento para la realización de las actividades.

Este proceso de articulación del GTANW en cada comunidad — que ocurre entre 2010 y 2015 - culmina con la asamblea general de las comunidades wampis en Soledad (Santiago) en donde cada jefe de comunidad ratifica su integración a la nación wampis y reconocen al GTANW como su máxima autoridad en agosto 
de 2015 (GTANW, s.f.). Este producto final implica no solo la construcción de nuevas instancias de organización política con base étnica y territorial, sino también una reconfiguración de la forma en la que enuncian y viven su relación con el Estado-nación.

\section{Conclusiones}

El caso de los wampis muestra la existencia de un sistema de vida material y espiritual relativamente autónomo hasta la década de 1950, siendo una trayectoria territorial indígena divergente para el proceso histórico peruano. Entre 1970 y 2000 van enfrentando de forma creciente la imposición de marcos de existencia desde el Estado y el capital, ante lo cual responden con modelos organizativos que no logran superar la atomización política en comunidades y federaciones. Consideramos que la estructura de oportunidad que abre el conflicto de Bagua en 2009 —entre policías e indígenas awajun y wampis- es un factor central a reconocer la posterior aparición de la estrategia contemporánea de autonomía indígena. Este suceso exacerba las tensas relaciones entre el Estado y los pueblos wampis, mostrando la insuficiencia de las vías estatales. Con mayor claridad se van mostrando incapaces de reconocer la legitimidad del uso territorial integral de los pueblos indígenas, lo que exige nuevas salidas políticas a las organizaciones. La apertura de la posibilidad de defensa de derechos de autogobierno a partir de los tratados internacionales y de las redes internacionales de apoyo a las organizaciones indígenas cristaliza esta estructura de oportunidad política de la politización de lo étnico para los pueblos amazónicos.

No obstante, el factor «impulsor» que explica este proceso es finalmente la agencia wampis. Este es un proceso de creación de agentes que no son «contenedores» vacíos o pasivos del desarrollo legal de los derechos indígenas a escala global. Los líderes wampis, al aprender los marcos legales acompañados de redes empoderadoras, fueron capaces de realizar un proceso de síntesis y traducción de la vivencia territorial wampis (sistema de vida), así como de los marcos estatales de existencia territorial que apropian y buscan replantear. Este es un mecanismo de creatividad política que aprovecha la estructura en la que se inscribe su acción, partiendo de ella para explorar nuevos marcos de legitimidad y existencia política que le permitan exigir y ejercer una gobernanza territorial indígena. Una lectura crítica de la ontología territorial estatal y la fuerza espiritual que otorga la visión de los ancestros en el territorio alimentan el concepto híbrido de territorio integral. Es decir, es el proceso de expandir lo políticamente posible desde dos bases ontológicas distintas: el sistema de vida wampis y las grietas de los marcos de existencia territorial del Estado.

Este proceso también muestra una forma de ejercicio de poder político indígena distinto a la de la «toma de poder» legal en el seno del Estado-nación. En este caso se 
encuentra la construcción de un poder público de carácter social, basado en la articulación de las bases desde las comunidades y cuencas, articuladas en torno a la noción de «nación wampis». Esto enfatiza la importancia de dar cuenta de la heterogeneidad de los procesos de política rural e indígena en el Perú, cuyas demandas no solo existen en la «intermediación» con los partidos políticos, sino también por medio de organizaciones que politizan el "contenido indígena» con implicancias sustanciales para sus formas de hacer política dentro y fuera del Estado. Una agenda de la investigación de la descolonización del Estado — desarrollo iniciado desde México, Ecuador y Bolivia - debe empezar a abordarse con seriedad en el Perú.

Asimismo, este caso permite entender la plasticidad de la relación que los pueblos indígenas en búsqueda de autonomía pueden construir con sus Estados-nación. El GTANW es un caso en donde la paradoja de inclusión y exclusión de los pueblos indígenas dentro del Estado (Merino, 2019) se puede ver con gran claridad, a diferencia del escenario latinoamericano, en donde ha primado la visibilización de procesos contraestatales o intraestatales.

No obstante, es importante reconocer que después del anuncio de la creación del GTANW aún queda un camino largo de implementación por recorrer. En cuanto a la recepción del Estado, con la excepción de la Municipalidad del Datem del Marańón ${ }^{11}$, las instancias de gobierno no se han pronunciado frente a la notificación de la creación del GTANW en junio de 2017. Además, existen zonas problemáticas en el territorio integral en Bajo Morona y Santiago, en donde organizaciones políticas y económicas no afines al GTANW —algunas relacionadas a economías extractivas ilegales - se mantienen. La unidad territorial y las alternativas productivas serán un reto enorme para la agenda autonómica, en un contexto de intensificación de la disputa territorial en el codiciado territorio amazónico.

\section{REFERENCIAS BIBLIOGRÁFICAA}

Abélès, M. y Badaró, M. (2015). Los encantos del poder: Desafios de la antropología politica. Buenos Aires: Siglo XXI Editores.

Ballón Aguirre, F. y López, E. M. (1987). Política de la supervivencia: las organizaciones de los pueblos indígenas de la Amazonía peruana. Apuntes. Revista de Ciencias Sociales, (20), 105-119. https://doi.org/10.21678/apuntes.20.251

Barclay, F. y Santos Granero, F. (1980). La conformación de las comunidades amuesha. La legalización de un despojo territorial. Amazonía Peruana, 3(5), 43-74. Recuperado de http://www.caaap.org.pe/RevistaAmazonia/AmazoniaPeruanaN\%C2\%B05.pdf

Barclay, F., Santos, F., Rodríguez, M. y Valcárcel, M. (eds.) (1991). Amazonia 1940-1990: El extravio de una ilusión. Lima: Terra Nuova y CISEPA-PUCP.

11 Que por medio de una ordenanza en 2017 reconoció al GTANW. 
Bebbington, A. J. y Bury, J. T. (2010). Minería, instituciones y sostenibilidad: desencuentros y desafíos. Anthropologica, 28(28), 53-84. Recuperado de http://revistas.pucp. edu.pe/ index.php/anthropologica/article/view/1371

Brass, T. (2012). Scott's «Zomia» or a Populist Post-modern History of nowhere. Journal of Contemporary Asia, (42), 123-133. https://doi.org/10.1080/00472336.2012.634646

Breton, V. (2009). La deriva identitaria del movimiento indígena en los Andes ecuatorianos o los límites de la etnofagia. En C. Martínez, Repensando losmovimientos indígenas (pp. 69-121). Quito: Flacso.

Brysk, A. (2000). From tribal village to global village: Indian rights and international relations in Latin America. Stanford: Stanford University Press.

Cavero, O. (2011). Movimiento indígena en el Perú: ¿trasnacional antes que local? En Nuevas miradas al Perú contemporáneo: movimientos sociales, identidad y memoria (pp. 175211). Lima: Programa Democracia y Transformación Social.

Chirif, A. (1997). Identidad y movimiento organizativo en la Amazonía peruana. Horizontes Antropológicos, 3(6) 135-159.https://doi.org/10.1590/s0104-71831997000200007

Chirif, A. (2012). Aidesep, una crisis de principios. Revista Ideele, 225-noviembre. Recuperado de https://revistaideele.com/ideele/content/aidesep-una-crisis-de-principios

Chirif, A. y Barclay, F. (2019). El lote 64, un mundo de conflictos. Afectaciones a los derechos indigenas achuar y wampis por las empresas GeoPark y Petroperú. Lima: Centro de Políticas Públicas y Derechos Humanos - Perú Equidad.

Clastres, P. (1974). La sociedad contra el Estado. Barcelona: Virus Editorial.

Cottyn, H. (2016). Renegotiating communal autonomy. Communal land rights and liberal land reform on the Bolivian altiplano. Carangas, 1860-1930. Gante, Bélgica: Ghent University. Faculty of Arts and Philosophy.

De la Cadena, M. (2016). Naturaleza disociadora. Boletín de Antropología. Universidad de Antoquia, 31(52), 253-263. https://doi.org/10.17533/udea.boan. v31n52a16

Delgado, G. (2015). The practice of autonomy by indigenous peoples. Latin American and Caribbean Ethnic Studies, 10(1), 146-154. https://doi.org/10.1080/17442222.201 5.1034435

De Sousa, B. (2004). Reiventar la democracia: reinventar el Estado. Quito: Abya Yala.

Diaz Polanco, H. (1992). Autonomía y cuestión territorial. Estudios Sociológicos, El Colegio de México. 10(28), 77-101. Recuperado de http://www.scielo.org.mx/scielo. php?script=sci_arttext $\&$ pid=S0187-01732015000100005

Fondo de las Naciones Unidas para la Infancia (Unicef) (2009). Informe 2009: Perú. Recuperado de https://www.unicef.org/peru/spanish/MEMORIA_UNICEF.pdf

García Hierro, P. y Surallés, A. (2009). Antropología de un derecho: libre determinación territorial de los pueblos indígenas como derecho humano. Lima: Alternativa Solidaria y el Grupo Internacional de Trabajo sobre Asuntos Indígenas (IWGIA).

Garra, S. y Riol, R. (2014). Por el curso de las quebradas hacia el «territorio integral indígena»: autonomía, frontera y alianza entre los awajún y wampis. Anthropologica, 32(32), 41-70. Recuperado de http://revistas.pucp.edu.pe/index.php/ anthropologica/article/view/9443. 
Gobierno Territorial Autónomo de la Nación Wampis (GTANW)(2017). Estatuto del Gobierno Territorial Autónomo de la Nación Wampis.

Gobierno Territorial Autónomo de la Nación Wampis (GTANW). (s.f.). Memorándum de actuandos.

Gómez, T.(2019). Reinventar el Estado desde la autonomía indígena: un rastreo del proceso de la articulación del Gobierno Territorial Autónomo de la Nación Wampis (GTANW) (tesis de licenciatura en Sociología). Facultad de Ciencias Sociales de la Pontificia Universidad Católica del Perú.

Gonzales, T.y González, M. (2015). Introduction. Indigenous peoples and autonomy in Latin America. Latin American and Caribbean Ethnic Studies. 10(1), 1-9. https:// doi.org/1 0.1080/17442222.2015.1034437

González, M. y Burguete Cal y Mayor, A. (2010). Introducción. En M. González, A. Burguete Cal y Mayor y P. Ortiz, La autonomía a debate: autogobierno indigena y Estado plurinacional en América Latina (pp. 9-34). Quito: Cooperación Técnica Alemana (GIZ): Grupo Internacional de Trabajo sobre Asuntos Indígenas (IWGIA), Centro de Investigaciones y Estudios Superiores en Antropología Social (CIESAS) y Universidad Intercultural de Chiapas(UNICH).

González, L. y Patiño, M. (2016). Noviolencia como alternativa de resistencia en Chiapas, México: el caso de Las Abejas de Acteal. Polis, 15(43), 181-201. https://doi. org/10.4067/S0718-65682016000100009

Greene, S. (2009). Caminos y carretera: acostumbrando la indigenidad en la selva peruana. Lima: Instituto de Estudios Peruanos.

Instituto del Bien Común (2020). Comunidades nativas georreferenciadas en campo: IBCSICNA. Enero 2020, incluye información levantada en gabinete, Aidesep-Cipta, GEF PNUD, Gorel y PFS.

Larson, A., Monterroso, I. y Cronkleton, P. (2017). Titulación colectiva en la Amazonia peruana: una historia en tres actos. Bogor, Indonesia: Center for International Forestry Research (Cifor). Recuperado de http://www.cifor.org/publications/pdf_ files/flyer/6915-flyer.pdf

Leal, D. B., Salisbury, D. S., Fernández, J. F., Pezo, L. C. y Silva, J. (2015). Ideas cambiantes sobre territorio, recursos y redes políticas en la Amazonia indígena: un estudio de caso sobre Perú. Journal of Latin American Geography, 14(2), 181-204. https://doi. org/10.1353/lag.2015.0018

Leifsen, E., Gustafsson, M., Guzman-Gallegos, M. y Schilling-Vacaflor, A. (2017). New mechanisms of participation in extractive governance: Between technologies of governance and resistance work. Third World Quarterly, 38(5), 1043-1057, https://doi. org/10.1080/01436597.2017.1302329

Lucero, J. A. (2008). Struggles of voice: The politics of Indigenous Representation in the Andes. Pittsburg: University of Pittsburg Press. https://doi.org/10.2307/j.ctt6wrd86

Merino, R. (2015). The politics of extractive governance: indigenous people and socio-environmental conflicts. The Extractive Industries and Society, 2(1), 85-92. https:// doi. org/10.1016/j.exis.2014.11.007 
Merino, R. (2019). El derecho y la política de la autodeterminación indígena: El significado del derecho a la consulta previa. Derecho y Sociedad, (51), 43-58. Recuperado de http://revistas.pucp.edu.pe/index.php/derechoysociedad/article/view/20857

Modonesi, M. (2010). Subalternidad, antagonismo, autononía: marxismos y subjetivación politica. Buenos Aires: Clacso y Prometeo Libros.

Monterroso, I., Cronkleton, P., Pinedo, D. y Larson, A.M. (2017). Reivindicación de derechos colectivos: Reformas de tenencia de tierras y bosques en el Perú (1960-2016). Documento de trabajo 227. Bogor: Center for International Forestry Research (Cifor).

Mora, M. (2015) The Politics of Justice: Zapatista Autonomy at the Margins of the Neoliberal Mexican State. Latin American and Caribbean Ethnic Studies, (10), 87-106. https:// doi.org/10.1080/17442222.2015.1034439

Morel, J. (2014). De una a muchas Amazonias: los discursos sobre "la selva» (19632012). En R. Barrantes y M. Glave (eds.), Amazonía peruana y desarrollo económico (pp. 21-46). Lima: Grupo de Análisis para el Desarrollo (Grade) e Instituto de Estudios Peruanos (IEP).

Movimiento Regional por la Tierra (2017). La nación wampis y su gobierno indígena. Movimiento Regional por la Tierra. Recuperado de https://porlatierra.org/novedades/ post $/ 237$

Paredes. M. (2010). En una arena hostil: la politización de lo indígena en el Perú. En C. Meléndez y A. Vergara (eds.), La iniciación de la política: el Perú político en perspectiva comparada (pp. 213-244). Lima: Fondo Editorial de la Pontificia Universidad Católica del Perú.

Paredes, A. y Li, F. (2017). Nourishing Relations: Controversy over the Conga Mining Project in Northern Peru. Ethnos, 84(2), 301-322. https://doi.org/10.1080/00141 844.2017.1410490

Pitman, N., Ruelas Inzunza, E., Alvira, D., Vriesendorp, C., Moskovits, D. K., del Campo, Á., ... Chase Smith, R. C. (eds.) (2012). Cerros de Kampankis. Rapid Biological and Social Inventories Report. Chicago: The Field Museum.

Programa de las Naciones Unidas para el Desarrollo (PNUD) (2013). IDH Perú 2013. Recuperado de https:/www.pe.undp.org/content/peru/es/home/library/poverty/ Informesobredesarrollohumano2013/IDHPeru2013.html

Postero. N. (2017). The indigenous state: race, politics, and performance in Plurinational Bolivia. Oakland: University of California Press. https://doi.org/10.1525/ luminos.31

Quijano, A. (2005). El «movimiento indígena» y las cuestiones pendientes en América Latina. En A. Quijano (2014), Cuestionesy horizontes: Antología esencial de la dependencia histórico-estructural a la colonialidad/descolonialidad del poder (pp. 635-663). Buenos Aires: Clacso.

Quijano, A. (1980). Lo público y privado: un enfoque latinoamericano. En A. Quijano (2014), Cuestiones y horizontes: Antología esencial de la dependencia histórico-estructural a la colonialidad/descolonialidad del poder (pp. 705-742). Buenos Aires: Clacso. 
Riol, R. (2015). La construcción del Cenepa como lugar indigena, una historia awajun y wampis de relación y defensa del territorio (tesis de doctorado en Antropología Social). Madrid: Universidad Autónoma de Madrid, Facultad de Filosofía y Letras.

Romio, S. (2014). Entre discurso político y fuerza espiritual: fundación de las organizaciones indígenas awajún y wampis (1977-1979). Anthropologica, 32(32), 139-158. Recuperado de http://www.scielo.org.pe/pdf/anthro/v32n32/a07v32n32.pdf

Romio, S. (2018). El "pre-Baguazo» y sus historias: anatomía de un conflicto (mayojunio 2009). Nuevo Mundo Mundos Nuevos \{en línea]. https://doi.org/10.4000/ nuevomundo.72918

Santos, V. y Renard, M. (2006). La relación identidad-cultura política en la formación de la autonomía indígena. Estudio de caso en una comunidad de los Altos de Chiapas. Ra Ximhai, 2(1), 73-95. https://doi.org/10.35197/rx.02.01.2006.05.vs

Scott, J. (2009). The Art of Not Being Governed: an anarchist history of Upland Southeast Asia. Londres: Yale University Press.

Schavelzon, S. (2012). El nacimiento del Estado plurinacional en Bolivia: etnografía de una asamblea constituyente. Buenos Aires: Clacso.

Surallés. A. (2009). Entre derecho y realidad: antropología y territorios indígenas amazónicos en un futuro próximo. Bulletin de l'Institut français d'études andines. (38), 29-45. https://doi.org/10.4000/bifea.2789

Surallés, A., Espinosa, O. y Jabin, D. (eds.) (2016). Apus, caciques y presidentes. Estado y politica indígena amazónica en los paises andinos. Lima: International Work Group for Indigenous (IWGIA), Instituto Francés de Estudios Andinos (IFEA) y Pontificia Universidad Católica del Perú (PUCP).

Surallés, A., Riol, R. y Garra, S. (2017). Informe antropológico sobre la continuada existencia de la nación wampis y su territorio: Fundamentación del derecho al territorio de la nación wampis. Gobierno Territorial Autónomo de la Nación Wampis (GTANW).

Tomic, C. (2015). Los límites de la autonomía indígena: territorios y actores ilegales en una subregión de la cuenca del Papaloapan, Veracruz, México. Ulúa, (26), 153-171). https://doi.org/10.25009/urhsc.2015.26.2256

Trampusch, C. y Palier, B. (2016). Between X and Y: how process tracing contributes to opening the black box of causality. New Political Economy, 21(5), 437-454. https:// doi.org/10.1080/13563467.2015.1134465

Tuesta, E. (2015). Perico, una persona entregada al mundo indígena. En A. Chirif (ed.), Querido Perico. Pedro Garcia Hierro, defensor de los derechos de los pueblos indígenas. Lima: International Work Group for Indigenous Affairs (IWGIA).

Van Cott, D. (2001). Explaining Ethnic Autonomy Regimes in Latin America. Studies in Comparative International Development, (35), 30-58. https://doi.org/10.1007/ BF02732707

Veber, H. y Virtanen, P. (2017) Introduction. En H. Veber y P. Virtanen (eds.), Creating dialogues. Indigenous perceptions and changing forms of leadership in Amazonia. Boulder: University Press of Colorado. https://doi.org/10.5876/9781607325604

Vega, I. (20 de agosto de 2018). Pueblos Awajún y Wampis ganan batalla histórica por su territorio: ordenan realizar consulta previa del lote 116. Centro Amazónico de Antropo- 
logía y Aplicación Práctica (CAAAP). Recuperado de http://www.caaap.org.pe/ website/2018/08/20/pueblos-awajun-y-wampis-ganan-batalla-historica-por-su-territorio-ordenan-realizar-consulta-previa-del-lote-116/

Yashar, D. (2005). Contesting Citizenship in Latin America: The Rise of Indigenous Movements and the Postliberal Challenge. Cambridge: Cambridge University Press. https://doi. org/10.1017/CBO9780511790966 